\title{
Transformation of Health in Turkey: Resistance Strategies of Health Workers Towards Symbolic Violence
}

\author{
Alev Akbal ${ }^{1}$ and Aytul Kasapoglu ${ }^{2 *}$ \\ ${ }^{1}$ University of Health Sciences, Gaziler Physical Theraphy and Rehabilitation Training and Research Hospital, Turkey \\ ${ }^{2}$ Department of Sociology, Baskent University, Turkey \\ *Corresponding author: Aytul Kasapoglu, Department of Sociology, Baskent University, Turkey
}

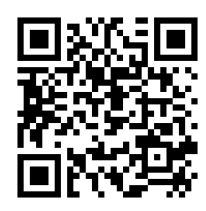

\section{ARTICLE INFO}

Received: 幽 January 14, 2020

Published: 輩 January 22, 2020

Citation: Alev Akbal, Aytul Kasapoglu. Transformation of Health in Turkey: Resistance Strategies of Health Workers Towards Symbolic Violence. Biomed J Sci \& Tech Res 24(5)-2020. BJSTR. MS.ID.004108.

\begin{abstract}
In this article, all over the world in parallel with the neoliberal policies which started to be implemented since 2002 in Turkey and identified as one of the most important health care reform "Transformation in Health Program" is due to bring the practices of health workers are exposed while performing their profession "symbolic violence" (Bourdieu, 1998) [1] and the resistance strategies developed by physicians, physiotherapists and nurses against this violence were examined comparatively. The findings of the study, which were based on in-depth interviews with 36 physicians, 22physiotherapists and 37 nurses, revealed that there were differences between health workers, although physicians behaved more rationally, nurses and physiotherapists mostly tried to cope with problems such as belief, conscience, and applying moral values.
\end{abstract}

Keywords: Health; Symbolic Violence; Health Professionals; Turkey

\section{Short Communication}

According to Bourdieu's $(1984 ; 1992)$ [2] theory, health is defined as "the structure in which a type of capital is distributed in a certain way." The symbolic power (state), which has the largest capital in the field of health as in other fields in the society (law, education, politics, religion, etc.), is making reforms in many subjects in order to maintain its sovereignty and legitimacy and to dominate its own view. Health, much less space than other autonomous areas such as literature and science, "Health Transformation Program in Turkey" with, redefined and shaped by the Ministry of Health. State with the capital in a legitimate manner to all health field (Bourdieu, 1992; 1998) [2], using the symbolic power (acceptance-approval on) the Health Transformation Program in Turkey has undertaken since 2003.

With the Health Transformation Program, a performance system based on revolving funds started to be implemented. However, this system not only led to a market-based understanding of health services, but also disrupted the existing peace among healthwork ers (Kasapoglu,2016) [3]. Sincethe targetedincrease in the number of health personnel, especiallyphysicians,couldnotbeachieved, health quality decreased and problems such as violence against health workers started to be experienced. The aim of this article is to describe in a comparative manner the strategies to resist symbolic violence that health workers are exposed to. As part of a wider study, qualitative data obtained from in-depth interviews with 36 physicians, 37 nurses and 22 physiotherapists after obtaining the necessary permissions were compared in this article.

\section{Results}

The strategies used by doctors, physiotherapists and nurses who have been subjected to symbolic violence while performing their occupations to balance the difficulties and professional principles are summarized in (Figure 1). Doctors state that they are trying to act professionally and empathize mostly by using their experience as the first strategy against symbolic violence. 


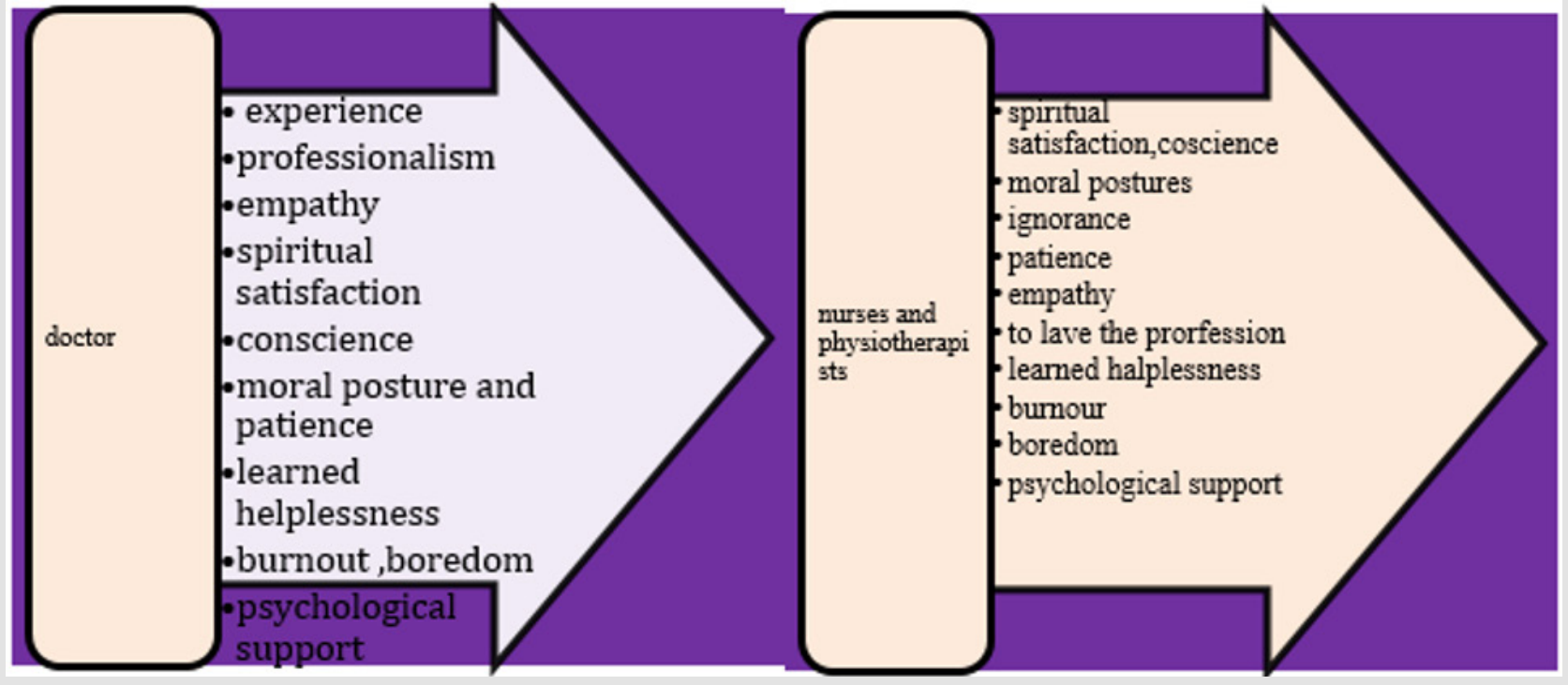

Figure 1: Physician and Non-Physician Staff Balancing Strategies of Professional Principles.

a. D16: I try to balance the challenges I face with my professional principles with great effort. You also learn to remain calm in the face of difficulties. Your own psychology is not valid at that moment, the patient's. You do empathy to protect yourself, not only by thinking about the patient, but also by being more effective. Experience is very important.

Unlike doctors, nurses and physiotherapists often use social values such as moral stance, spiritual satisfaction and conscience as the first strategy in dealing with symbolic violence. Experience and professional behavior for physiotherapists gain importance with social values and it is claimed that doctors behave more professional than physiotherapists.

1. F12: I think there is faith and suggestion here. I have to do my job perfectly and deserve this money. Halal money, conscience, faith, suggestion makes me do this profession. We are dealing with some experience and experience.

2. F20: Professional approach or conscience comes into play, in physiotherapist conscience is more dominant. Doctor performs intestinal surgery, professionalism is in the foreground, we work with amateur spirit, our conscientious abilities come to the fore. There is a conscience in the nature of the physiotherapist. Sensitivity in religious matters is also effective.

3. N10: You get angry, you yell, but when you see the patient, it's all over. Conscientious responsibility weighs so much that you try not to make mistakes.

4. N33: With prayer from patients. Satisfaction, spirituality is very important. The things you gain from spirituality will straighten you out.
Physicians' strategy of social values such as conscience and morality against symbolic violence comes after professionalism.

a. D26: When I go home from work in the evening, is my conscience comfortable, it's important, have I looked at all the patients, answered questions, left all satisfied, I ask.

The majority of the doctors interviewed stated that they faced negative processes such as burnout, boredom, stress and depression in the face of symbolic violence and received psychological support.

1. D14: I think we can't overcome the difficulties, tension, stress, depression, fatigue, these affect us, we are not happy, in general, I think all physicians are unhappy.

2. D10: I use antidepressants because my endurance to my son is diminishing. When my compulsory service is over, if it continues like this, I will resign and look for another way.

A significant number of physiotherapists and nurses (58\%) who stated that they could not cope with symbolic violence claim that they received psychological support or burnout / boredom / stress syndrome.

a. F14: I can't handle it, I'm getting psychological support, I can't stand it. I can't find what makes me happy anymore, I love my job, but I'm bored. I'm not comfortable doing the job. I have to do within certain patterns, I have to pay attention to everything. I feel like I hit the bottom.

b. F6: We have a manic-depressive condition, we're not good, I really feel it. The laws are arranged for doctors. All this makes us feel under pressure.

c. N12: We can't stabilize, we're constantly throwing ourselves inside, we're bursting somewhere, it's both 
psychological and physiological damage. You compromise yourself; your psychology is turned upside down; we go home in the evening with all sorts of muscular pain.

d. N26: We can't fight this conflict, we're going crazy. So, I think $98 \%$ of nurses have burnout syndrome.

e. N34: Psychological distress is very high in nurses. If the statistics are made, six out of 10 nurses use antidepressants.

However, some of the nurses ignore symbolic violence by accepting that the process will not change in the face of symbolic violence (obedience-consent).

1. N16: We can't handle it much; we're doing what we're talking about.

2. N31: That's our job, we say we have to do it, we try to rule them out as much as we can, we don't think about troubles and pretend we don't.

Some of the employees accept and consent to the program, while those who do not accept ignore the processes imposed on them due to the legitimacy of the program.

\section{Conclusion}

According to Bourdieu (1992;1998) [2], believing and obeying the state is one of the most important features of the state hegemony. Moreover, it does so with a magical power without constantly ordering or resorting to physical violence. This power is the symbolic capital power in the hands of the state. Symbolic violence is the process of transforming itself into a charm or charisma by misrepresenting the relations of domination and submission to symbolic power (Bourdieu, 1998) [1]. Neither does the perpetrator of symbolic violence nor does he realize that he is subjected to symbolic violence. Weberyan (2005) [4], with a

ISSN: 2574-1241

DOI: 10.26717/BJSTR.2020.24.004108

Aytul Kasapoglu. Biomed J Sci \& Tech Res

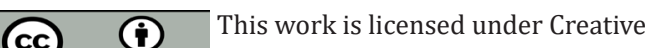
Commons Attribution 4.0 License

Submission Link: https://biomedres.us/submit-manuscript.php glance, provides a legitimate order (the Health Transformation Program) to force people to obey. While symbolic violence can only be applied to agents that are prone to feeling itself, others ignore it, but they accept it (Bourdieu, 1991) [5]. In providing this service, doctors often resort to professionalism and experience in balancing symbolic violence with their professional principles; Physiotherapists and nurses often balance their professional principles by clinging to social values such as faith, conscience and morality. Religious capital, in particular, has an important influence here. Social values make employees' choices seem to be a virtue. In this way, it helps them accept the domination of symbolic power. Physiotherapists are in constant struggle with doctors who are thought to have capital differences.

The Health Transformation Program, prepared by the symbolic power to legitimize its own worldview, leads to conflict situations that confront health professionals with their professional principles. In this case, health workers state that they have been exposed to processes such as burnout, boredom, depression or they have coped with psychological support. Regardless of the method of coping with symbolic violence, the symbolic system is accepted, consented by health workers, that is to say, through laws, powers and capitals of symbolic power, symbolic violence occurs.

\section{References}

1. Bourdieu P (1998) Practical Reason: On the Theory of Action (Trans. R. Johnson), Stanford University, California, USA.

2. Bourdieu P (1992) The Logic of Practice (Trans. R.Nice) Polity, Cambridge, UK.

3. Kasapoğlu A (2016) Türkiye'de Sağlık Hizmetlerinin Dönüşümü (Transformation of Health Services in Turkey). Sosyoloji Araștırmaları Dergisi 19(2): 131-174.

4. Weber M (2005) Bureaucracy and Authority (Trans. H.B. Akın), Ankara: Address.

5. Bourdieu P (1991) Language and Symbolic Power, Cambridge: Polity.

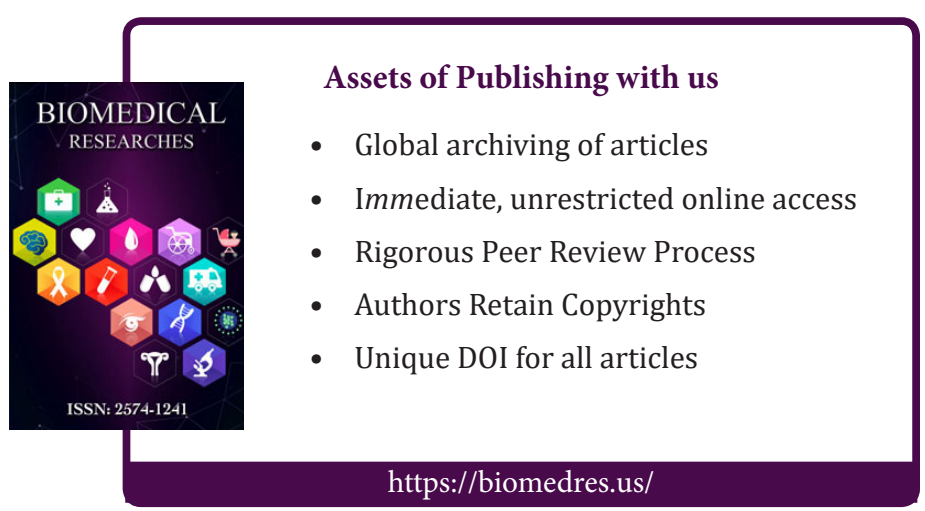

